\title{
Editorial
}

Journal of

Molecular Microbiology

and Biotechnology
J Mol Microbiol Biotechnol 2006;11:289-290

DOI: $10.1159 / 000095630$

\section{The Bioinformatic Study of Transmembrane Molecular Transport}

Membrane transporters are the cell's equivalent of delivery vehicles, garbage disposals, and communication systems - proteins that span the cell membrane and form an intricate system of pumps and channels through which they deliver essential nutrients, eject waste products, and assist the cell to sense environmental conditions. Membrane transport systems play indispensable roles in the fundamental cellular processes of all organisms. Knowledge of the suite of transporters present in an organism sheds light on its lifestyle and physiological adaptations. Until recently, analyses of membrane transporters have been limited primarily to the examination of transporter genes in individual organisms. However, with the advent of the genomics era, comprehensive bioinformatic comparisons of predicted membrane transporters across a range of organisms in all three domains of life have become possible.

New computational application of the phylogenetic profiling approach to cluster organisms together that appear to have similar suites of transporters provides an even more recent advance. For example, obligate intracellular pathogens and endosymbionts possess limited numbers of transport systems in spite of the massive metabolite fluxes one would expect between the pathogens or symbionts and their hosts. This is believed to be due to the relatively static nature of their intracellular environments which require minimal degrees of adaptation, particularly to stress conditions. Limited types of nutrients need to be taken up, which are provided by the host in nearly constant amounts. Because the host provides a homeostatic home, the bacteria can streamline their genomes and eliminate excess baggage. The consequence is a bacterium that can live only in one or a few host organisms.
To provide the research community as well as the general public with easy access to the extensive information about transporters, web-based databases have been created. These include the Transporter Classification Database (TCDB) (http://www.tcdb.org) which classifies transport proteins based on both function and phylogeny, and the TransportDB Database (http://www.membranetransport.org/) which surveys fully sequenced genomes for genes encoding transport proteins. In the latter database, the transporter profiles of each sequenced organism are available to view, search, compare, and download in an easy-to-navigate format. Extensive links and references are also provided on the site. This is the only active database dedicated to the comprehensive, comparative study of membrane transporters in different organisms with fully sequenced genomes. In the former database (TCDB), over 400 families of transporters are described, and functional data for representative wellcharacterized members of these families are provided. When possible, these families have been grouped into superfamilies that define the evolutionary relationships between individual families. Web-based search tools and useful bioinformatic software packages render TCDB user-friendly. There is also a major section devoted to poorly characterized families of transport or putative transport proteins where more studies are needed. TCDB and TransportDB are tremendous resources both for research scientists and for students and their teachers. Thousands of researchers visit these databases on the web regularly and have applied the information provided to their research efforts. The availability of these databases has inspired numerous laboratory studies on membrane transporters, promoting the rapid expansion of this area of research.

\begin{tabular}{ll}
\hline KARGER & (c) 2006 S. Karger AG, Basel \\
Fax +41 61 306 1234 $34-1801 / 06 / 0116-0289 \$ 23.50 / 0$ \\
$\begin{array}{l}\text { E-Mail karger@karger.ch } \\
\text { www.karger.com }\end{array}$ & $\begin{array}{l}\text { Accessible online at: } \\
\text { www.karger.com } / \mathrm{mmb}\end{array}$
\end{tabular}


Out of the hundreds of thousands of proteins encoded in bacterial, archaeal and eukaryotic genomes, over 10\% function in transport. Transport systems employ a large variety of mechanisms to import various ions and nutrients and to prevent the excessive build-up of other ions, end products of metabolism, toxins and drugs. It is hoped that someday, the identification of the complete complement of transporters in sequenced genomes will become possible.

Currently over 300 fully sequenced genomes are available for analysis. Many of the encoded transporters have been classified into different families, and their functions have been predicted. Interdisciplinary expertise in genomics and bioinformatics allows the development of computational tools and models that should expedite, improve and advance traditional biological studies of transporters.

Genome sequencing projects have had a tremendous impact on medical and environmental microbiology. For example, the genome sequencing of a methanotrophic bacterium, Methylococcus capsulatus, which feeds off of methane, one of the major greenhouse gases, is of importance because of its potential to mitigate global warming, a problem that we will face on an ever increasingly intense scale in the future. The genome sequence of this bacterium has allowed biologists and environmental bioengineers to focus on an understanding of the parameters of this organism in an effort to utilize it and other bacteria for solutions to our real-life environmental problems.
M. capsulatus relies heavily on its large repertoire of metal cation pumps (12 P-type cation ATPases, 4 of which have a copper-binding P-ATPase motif) to take up copper ions for the regulation of methane oxidation, a critical step in methane metabolism. In contrast, this organism possesses very few transport systems for organic carbon compounds, which emphasizes the importance of methane as its sole carbon source for energy production and growth. This is yet another example illustrating the relevance of transport protein profiles to the overall physiology of organisms. These findings, combined with bioinformatic analyses of metabolic features, deepen our understanding of methanotrophic lifestyles and emphasize this bacterium's potential for biotechnological applications that could lead to environmental improvements.

In conclusion, studies at all levels, including genetic, biochemical, biophysical and physiological, allow computational microbiologists to view a living organism as a complete system communicating with its environment. The implications with respect to improvement of the environment and global biosphere healthcare systems are staggering. Novel techniques will allow the more rapid advance of scientific discovery leading to solutions to our immense environmental and health problems.

\author{
Milton H. Saier, Jr., Editor-in-Chief \\ Qinghu Ren, Staff Scientist \\ The Institute for Genomic Research (TIGR)
}

\section{References}

Busch, W. and Saier, M.H., Jr. (2002). The Transporter Classification (TC) System, 2002. CRC Crit Rev Biochem Mol Biol 37:287337.

Chang, A.B., Lin, R., Studley, W.K., Tran, C.V., and Saier, M.H., Jr. (2004). Phylogeny as a guide to structure and function of membrane transport proteins. Mol Membr Biol 21:171-181.

Paulsen, I.T., Nguyen, L., Sliwinski, M.K., Rabus, R., and Saier, M.H., Jr. (2000a). Microbial genome analyses: comparative transport capabilities in eighteen prokaryotes. J Mol Biol 301:75-100
Ren, Q., Kang, K.H., and Paulsen, I.T. (2004) TransportDB: a relational database of cellular membrane transport systems. Nucleic Acids Res 32:D284-D288 (database issue).

Ren, Q. and Paulsen, I.T. (2005). Comparative analyses of fundamental differences in membrane transport capabilities in prokaryotes and eukaryotes. PLoS Comput Biol 1:190201.

Saier, M.H., Jr. (2000). A functional-phylogenetic classification system for transmembrane solute transporters. Microbiol Mol Biol Rev 64:354-411.

Saier, M.H., Jr., Tran, C.V., and Barabote, R.D. (2006). TCDB: The transporter classification database for membrane transport protein analyses and information. Nucl Acids Res 34:D181-D186 (database issue).
Ward, N., Larsen, O., Sakwa, J., Bruseth, L., Khouri, H., Durkin, A.S., Dimitrov, G., Jiang, L., Scanlan, D., Kang, K.H., Lewis, M., Nelson, K.E., Methe, B., Wu, M., Heidelberg, J.F., Paulsen, I.T., Fouts, D., Ravel, J., Tettelin, H., Ren, Q., Read, T., DeBoy, R.T., Seshadri, R., Salzberg, S.L., Jensen, H.B., Birkeland, N.K., Nelson, W.C., Dodson, R.J., Grindhaug, S.H., Holt, I., Eidhammer, I., Jonasen, I., Vanaken, S., Utterback, T., Feldblyum, T.V., Fraser, C.M., Lillehaug, J.R., and Eisen, J.A. (2004). Genomic insights into methanotrophy: the complete genome sequence of Methylococcus capsulatus (Bath). PLoS Biol 2:e303 (Epub). 